Old Dominion University

ODU Digital Commons

ODU Articles

ODU Resilience Collaborative

2018

\title{
An Intergovernmental Blueprint for Community Resiliency: The Hampton Roads Sea Level Rise Preparedness and Resilience Intergovernmental Pilot Project
}

Ray Toll

Old Dominion University, rtoll@odu.edu

Follow this and additional works at: https://digitalcommons.odu.edu/odurc-articles

Part of the Oceanography and Atmospheric Sciences and Meteorology Commons, and the Public Affairs, Public Policy and Public Administration Commons

\section{Repository Citation}

Toll, Ray, "An Intergovernmental Blueprint for Community Resiliency: The Hampton Roads Sea Level Rise Preparedness and Resilience Intergovernmental Pilot Project" (2018). ODU Articles. 1.

https://digitalcommons.odu.edu/odurc-articles/1

\section{Original Publication Citation}

Toll, R. (2018). An intergovernmental blueprint for community resiliency: The Hampton Roads Sea Level Rise Preparedness and Resilience Intergovernmental Pilot Project. Marine Technology Society Journal, 52(2), 7-9. doi:10.4031/MTSJ.52.2.1

This Editorial is brought to you for free and open access by the ODU Resilience Collaborative at ODU Digital Commons. It has been accepted for inclusion in ODU Articles by an authorized administrator of ODU Digital Commons. For more information, please contact

digitalcommons@odu.edu. 


\title{
An Intergovernmental Blueprint for Community Resiliency: The Hampton Roads Sea Level Rise Preparedness and Resilience Intergovernmental Pilot Project
}

\author{
Ray Toll \\ Director Coastal Resilience Research, \\ Office of Research, \\ Old Dominion University \\ Immediate Past President, \\ Marine Technology Society
}

\begin{abstract}
his special Marine Technology Society (MTS) Journal issue on resilience features authors presenting various perspectives on the challenges and solutions that we all must face. Many of these perspectives are a follow-up to the recommendations from a 2014-2016 pilot run by Old Dominion University (ODU) that used a whole-of-government/community approach to an integrated regional solution in Hampton Roads. An intergovernmental blueprint for community resiliency, The Hampton Roads Sea Level Rise Preparedness and Resilience Intergovernmental Pilot Project (convened by ODU and launched in June 2014 with MTS), was one of the three White House National Security Council pilots and one of the three Department of Defense pilots in response to the 2013 Presidential Executive Order, "Preparing the U.S. for the Impacts of Climate Change" (http://www.centerforsealevelrise.org/).

Two key national leaders, Secretary of State John Kerry and Assistant Secretary of the Navy for Installations, Energy and Environment Dennis McGinn, touted this effort as an effective process to both mitigate and adapt to rising sea levels and to address both national security and economic impact concerns. They went on to say that the ideas of an integrated regional approach could serve as an effective and efficient building block for a national water plan, providing a template for other regions of the country and overseas, particularly where our Navy has a presence.
\end{abstract}

\section{Background}

It was fitting that ODU would be the chosen site to convene this effort; situated in Norfolk, Virginia, the university is $20 \mathrm{~min}$ from the largest naval base in the world. ODU President John Broderick announced in 2009 that sea level rise (SLR) would be a research and academic priority for years to come. Boasting the largest natural coastline in the world, southeastern Virginia has an economy and culture tied largely to the strength of its ports and waters. The Hampton Roads region's geography has attracted multiple military installations, including the naval 
base, and also encompasses the third largest commercial harbor on the eastern seaboard, manufacturing facilities, commercial fisheries, residential development, and tourism.

ODU and MTS began partnering in 2012 with the OCEANS 2012 conference (http:// hamptonroads12.oceansconference.org). This annual MTS/IEEE meeting highlighted coastal resiliency as a regional priority, as many technical papers were presented on the topic from the 3,000 conference delegates representing 35 countries. In June 2014, MTS cosponsored the pilot rollout on campus with a TechSurge workshop (http:// mtshamptonroads.org/mtshr/?page_id=389).

From 2014 to 2016, Hampton Roads localities including Virginia Beach and Norfolk, four Cabinet Departments of Virginia Governor Terry McAuliffe, 11 federal agencies (including the Department of Defense), the Virginia Port Authority, a variety of private businesses, and three nonprofits worked together on a White House-announced intergovernmental pilot project (IPP) convened by ODU to figure out how to build coastal resilience in the face of increasing SLR (Figure 1).

\section{FIGURE 1}

Project interaction map. 


\section{Whole of Government and Community}

The goal of this initiative was to establish an intergovernmental planning process to effectively coordinate SLR preparedness across multiple federal, state, and local government agencies as well as the private and nonprofit sectors, while taking into account perspectives and concerns of the region's citizens.

Led by a steering committee, volunteers focused on legal issues, infrastructure requirements, citizen engagement, public health, science, and economic impacts. Several aspects are worth mentioning:

- linking infrastructure interdependencies (on and off base) by sharing maps, plans, etc., with neighboring jurisdictions and municipalities;

- creating and maintaining an integrated regional network to observe impacts to the economy, storm water, public health, and infrastructure (these data could be used in real time but also archived to properly monitor longer-term changes at a greater level of spatial and temporal fidelity);

- incentivizing "whole-of-government" practices for each municipality through grants, requests for proposals, and other federal and non-federal acquisition practices;

- integrating planners' and emergency managers' plans and procedures to address realtime threats (such as Hurricanes Sandy and Matthew) and long-term trends like SLR; and

- improving scientific research methods through data integration and model improvement. Upon completion of the pilot project, Hampton Roads will have laid the groundwork for a regional whole-of-government and whole-of-community organizational framework and procedures that effectively coordinate SLR preparedness and resilience planning. An important next step is a U.S. Department of Transportation initiative to quantify climate change impacts. Federal transportation officials chose Hampton Roads for this work and were proactive partners throughout the 2-year pilot effort (2014-2016).

The papers that follow present early results from research that addresses various aspects of the challenge from a whole-of-community perspective using a multidisciplinary approach. The College of William \& Mary's Virginia Institute of Marine Science and Virginia Coastal Policy Center were key partners during the entire IPP. 


\section{nsasjhe techsology socIETY}

The International, Interdiscipl parry Society Devoted to Ocean and Marine Engineering, Science, and Policy
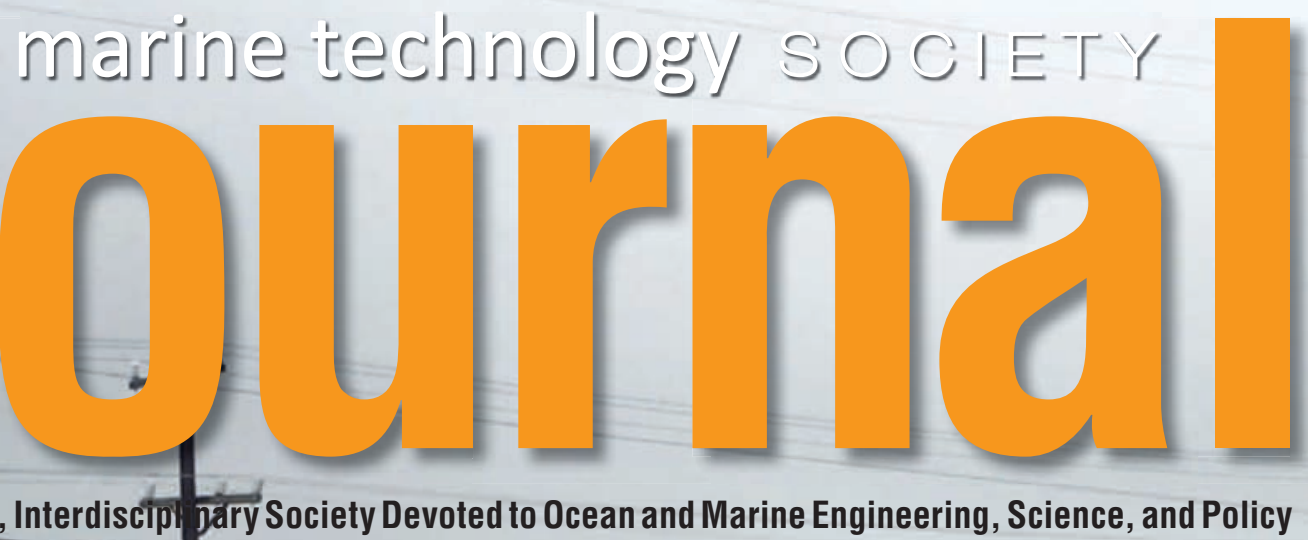

Volume 52 Number 2 March/April 2018.

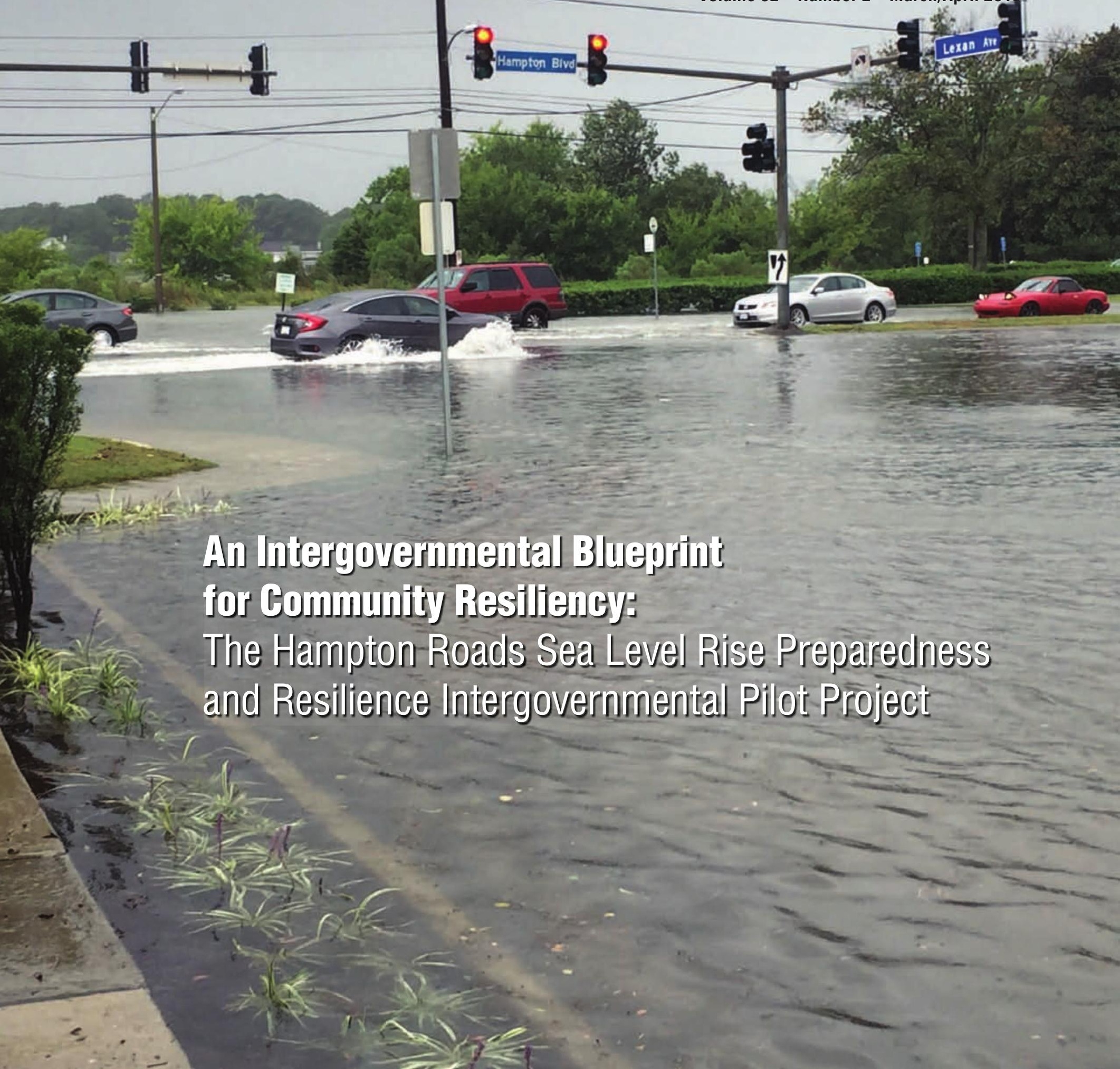


marine technology S O CIETY 1100 H Street NW, Suite LL-100

Washington, DC 20005
Postage for periodicals

is paid at Washington, DC and additional mailing offices.
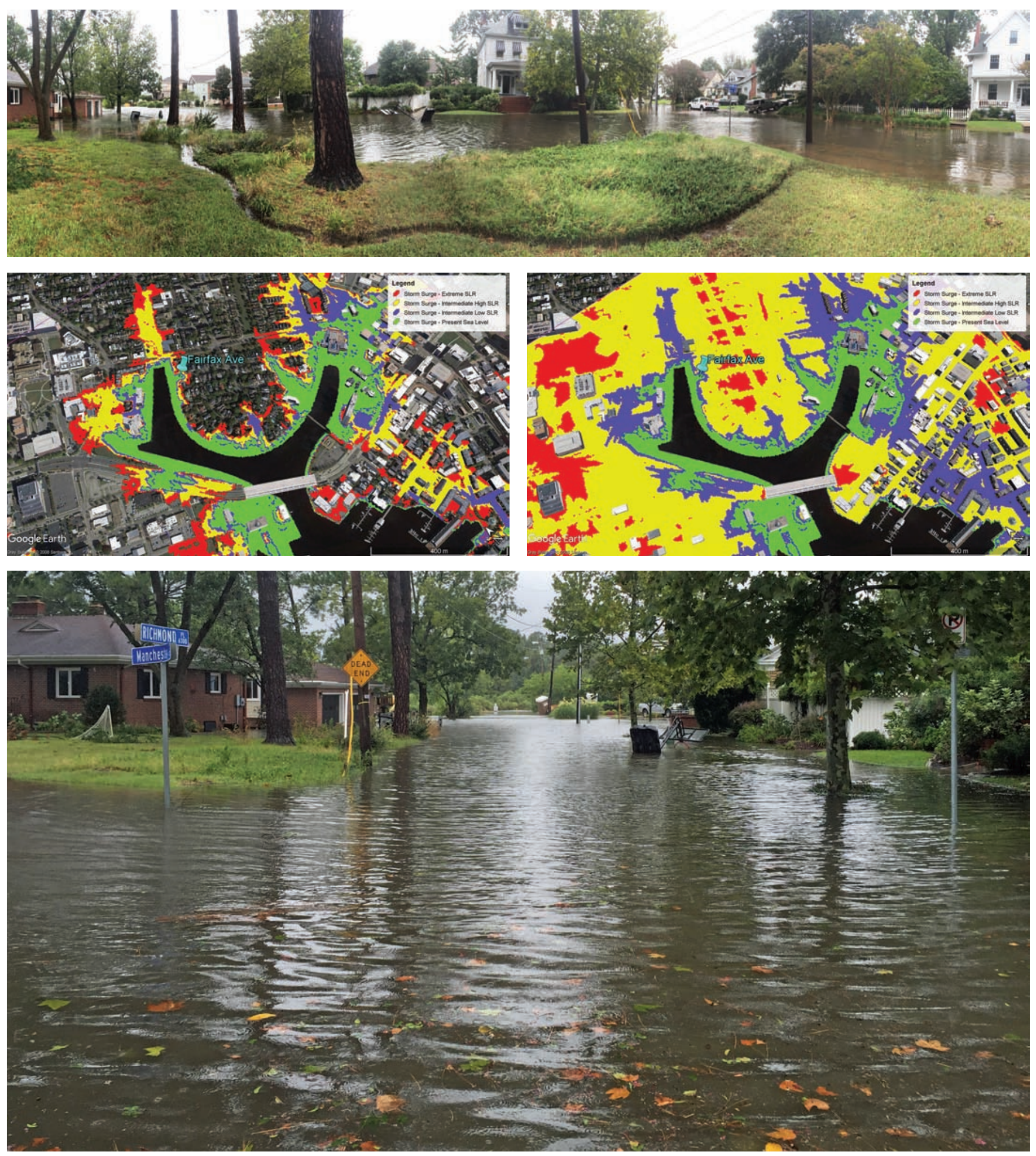